\title{
Thermal nondestructive evaluation of copper products using an infrared line scanning technique
}

\author{
by J. Varis ${ }^{1}$ and J. Rantala ${ }^{2}$ \\ ${ }^{1}$ Department of Physics, P.O. Box 9, FIN-00014 UNIVERSITY OF HELSINKI, Finland \\ ${ }^{2}$ Nokia Research Center, P.O.Box 407, FIN-00045 NOKIA GROUP, Finland
}

\begin{abstract}
Defect detection in copper products was studied in laboratory conditions by using an infrared line scanning system. Finite difference calculations were carried out to estimate the surface temperature increase caused by delaminations. In the experiments, elongated delaminations, small voids, and air bubbles were found in the copper samples.
\end{abstract}

\section{Introduction}

Copper products are used in a variety of industrial applications like heat sinks, electrical components, etc. The copper manufacturer usually produces long tubes or wires having different kinds of cross-sections, depending on the needs of the end user. The wire is drawn at high speeds, and the mechanical tensions inside the wire can generate defects. The usual defect types are delaminations or voids. The high drawing speed causes the delaminations to be several metres in length, whereas the voids are usually smaller having the size of a few square millimeters. These voids trap air inside them. The end user cuts suitable pieces out of the wire to make the copper products. If heat is applied to the surface of a defective product, such as when soldering another wire, the surface may burst open, rendering the component useless.

The process of making the copper wire applies a lot of heat on the raw copper material. Later the wire is cooled by liquid and air jets. Especially after the air jet cooling, the conditions are suitable for defect detection using infrared thermography. In the case for which the copper wire moves during the manufacturing process like on a conveyor belt, an infrared line scanning technique [1] has been proposed for the detection task. Here, preliminary studies in laboratory conditions are reported.

\section{Numerical model}

Temperature increase caused by delaminations in a copper sample was estimated by carrying out finite difference calculations [2]. In the calculations, a model of $20 \times 240 \times 15$ grid points (Fig. 1), corresponding to a physical size of $11 \mathrm{~mm} \times 50 \mathrm{~mm} \times 6 \mathrm{~mm}$, was used. The model was divided into two layers, of which the top layer was $0.5 \mathrm{~mm}$ thick. In both layers, the thermal characteristics were: density $8933 \mathrm{~kg} \mathrm{~m}^{-3}$, specific heat $385 \mathrm{~J} \mathrm{~kg}^{-1} \mathrm{~K}^{-1}$, and thermal conductivity $401 \mathrm{~W} \mathrm{~m}^{-1} \mathrm{~K}^{-1}$. A delamination was simulated by placing a contact resistance of $R_{C}=10^{-4} \mathrm{~m}^{2} \mathrm{KW}^{-1}$ between the $x y$ grid point planes of the first and the second layer. The $R_{C}$ value used corresponded to a severe delamination. The surface plane was heated with a line source moving in the $y$-direction. The width of the heating line was $3 \mathrm{~mm}$, and the heating power was $100 \mathrm{~W}$, chosen to simulate a hot air jet. Two velocity values were used. The first value of $2 \mathrm{~mm} / \mathrm{s}$ corresponded to the actual velocity in the laboratory experiments, whereas the second value of $2.5 \mathrm{~m} / \mathrm{s}$ was chosen to simulate the industrial conditions for comparison.

Figures $2 a$ and $b$ show the curves for surface temperature $T$ and the temperature difference $\Delta T$ as obtained from the numerical computations in the cases of both velocities. The temperature difference caused by the delamination was calculated by subtracting the temperature values of a faultless sample $\left(R_{C}=0\right)$ from the corresponding values of the sample with the contact resistance of $R_{C}=10^{-4} \mathrm{~m}^{2} \mathrm{KW}^{-1}$. At the lower velocity, the temperature increase caused by the delamination is significant, as shown in Fig. $2 a$. 
The peak value of $\Delta T$ occurs about $0.4 \mathrm{~mm}$ behind the heating line centre, indicating the best position for detection in the experiments. However, the optimum distance from the line source centre is not critical, because the temperature difference stays high several millimeters behind the centre. In the case of the higher velocity (Fig. 2b), the optimum detection point is now $4.6 \mathrm{~mm}$ behind the line source centre. Unfortunately, the peak value of $\Delta T$ is only $0.2 \mathrm{~K}$, which may stay undetected experimentally. On the other hand, the heating power of $100 \mathrm{~W}$ is underestimated for industrial conditions.

\section{Experimental setup}

In the experiments, the $11 \mathrm{~mm}$ wide and $6 \mathrm{~mm}$ thick copper samples were heated by applying a hot air jet directed through a "fish tail"-shaped nozzle on the sample surface (Fig. 3). The sample was moved perpendicularly to the nozzle with a translation stage. Simultaneously, the surface temperature of the copper was monitored alongside the nozzle with an infrared line scanner. The scanner consisted of a liquid nitrogen cooled HgCdTe detector, a Ge lens, and a deflection mirror. The size of the detector was $25 \mu \mathrm{m} \times 25 \mu \mathrm{m}$, and the focal length of the lens was $25 \mathrm{~mm}$. A microcomputer was used for controlling the translation stage, the deflection mirror, and the data acquisition from the detector. The surface temperature was sampled in 180 points alongside the nozzle, and 280 image lines were recorded during the translation of the sample. The computer combined the lines into a pseudo colour image.

\section{Results}

Examples of results are shown in Figs. $4 a$ and b. The sizes of the imaged areas shown in the thermal images were $16 \mathrm{~mm} \times 9 \mathrm{~mm}$. The scanning velocity was $2 \mathrm{~mm} / \mathrm{s}$. The higher velocity of $2.5 \mathrm{~m} / \mathrm{s}$ was not applied in the laboratory experiments. In Fig. $4 \mathrm{a}$, an elongated delamination can be seen as a hotter (light gray) area near the top edge of the thermal image. However, the temperature increase seen in the image is quite small compared to the numerical estimates. The temperature increase is higher (white) in the case of voids or bubbles, which can be seen in the middle of Fig $4 a$, and in the thermal image shown in Fig. 4b. Most likely the voids are located closer to the sample surface than the delamination. According to the manufacturer, the depth of the delaminations is usually $0.5 \mathrm{~mm}$. Both the images show a lot of surface features as well, which has been further enhanced by the edgefinding filter applied to the images. Copper is a soft metal and it scratches easily. Also, the copper samples get oxidized fast, and as result the surface of the copper show local variations in emissivity. Fortunately, these problems will not affect the measurements in the industrial conditions, because the surface of the copper wire will not have enough time to get damaged before the inspection.

\section{Discussion}

Preliminary studies of copper products show that voids or bubbles can easily be resolved in laboratory conditions. Faint traces of the elongated delaminations can be seen as well, but generally speaking, the samples suffer from surface features, which complicate the interpretation of the thermal images. In the future, these problems are not expected to affect the measurement, since the newly produced copper product will not have been tainted yet. However, the numerical estimates foresee another problem, namely the lack of contrast, due to high imaging speeds. Fortunately, it is possible to increase the amount of heating power directed to the sample surface, and hopefully, the problem will not be too serious to overcome.

\section{REFERENCES}

[1] HARTIKAINEN (J.) - Rev. Sci. Instrum. 60, 1989, p. 1334.

[2] VARIS (J.), RANTALA (J.), and HARTIKAINEN (J.) - Res. Nondestr. Eval. 6, 1995, p. 69. 
http://dx.doi.org/10.21611/qirt.1998.010

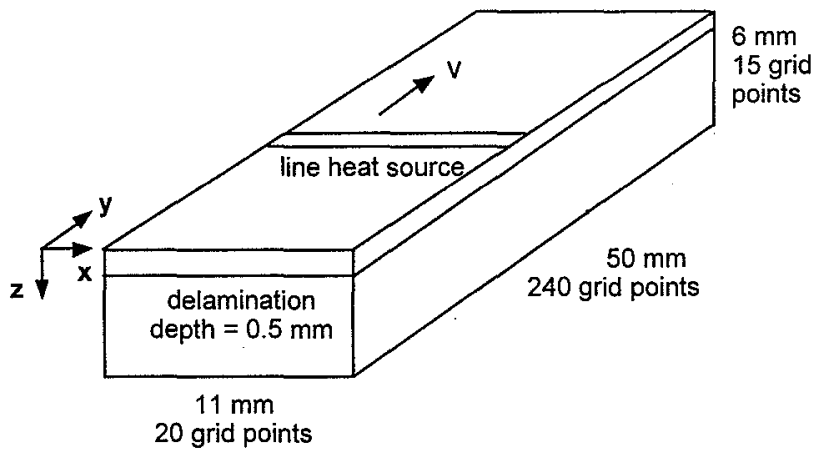

Fig. 1. The numerical model of the copper sample

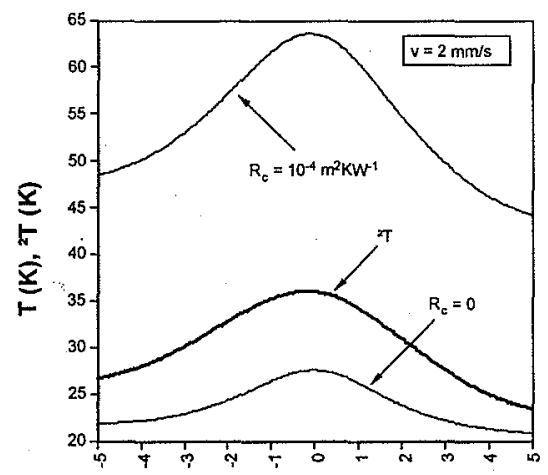

a)

Distance from heat source center (mm)

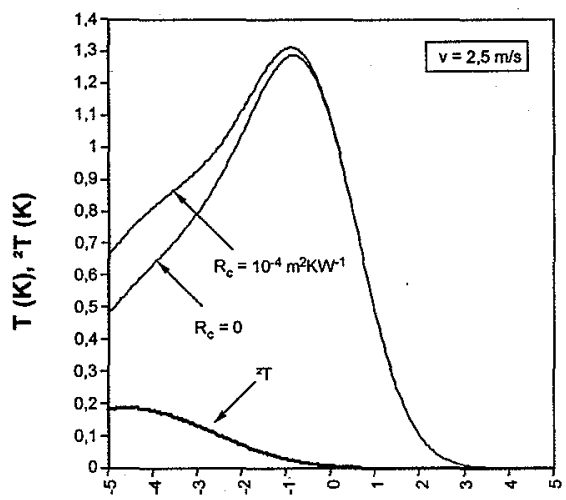

b)

Distance from heat source center (mm)

Fig. 2. The surface temperature and the surface temperature difference curves obtained from the finite difference computations. The results are shown in the cases of heat source velocities of a) $2 \mathrm{~mm} / \mathrm{s}$ and b) $2.5 \mathrm{~m} / \mathrm{s}$. 
http://dx.doi.org/10.21611/qirt.1998.010

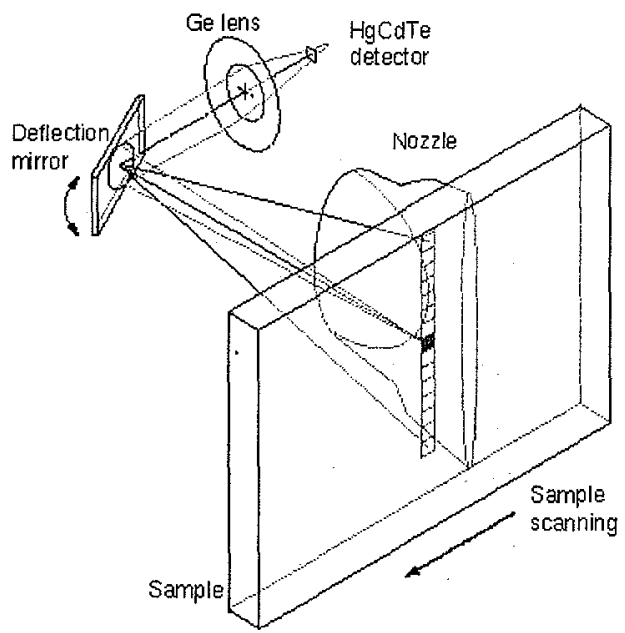

Fig. 3. The principle of the infrared line scanning measurement system

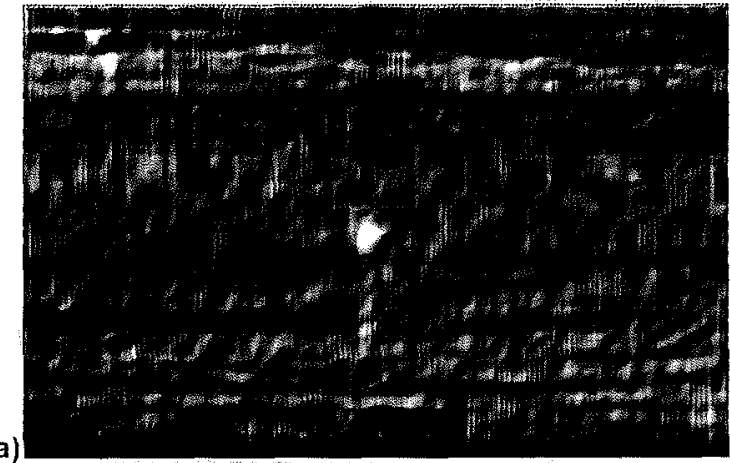

a)

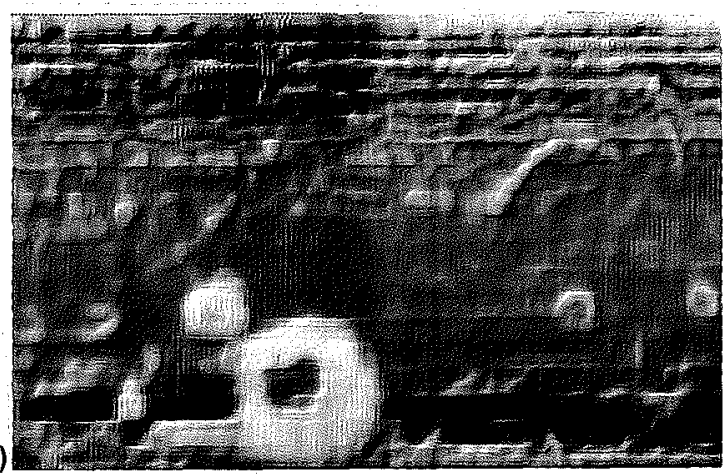

Fig. 4. a) A thermal image showing an elongated delamination in the copper sample. The delamination is located near the upper edge of the image. A small void can be seen in the middle of the image as well. b) A thermal image of an air bubble in the copper sample. The imaged area is $16 \mathrm{~mm} \times 9 \mathrm{~mm}$ in both the images. An edge enhancing filter has been applied to both the images. 